\title{
Evaluation of antidiabetic activity in Corallocarpus epigaeus rhizomes
}

\author{
Kattamanchi Gnananath ${ }^{1}$, Kontham Ramakanth Reddy ${ }^{1}$, Gudur Pavan Kumar ${ }^{1}$, Bheemanapally Krishna ${ }^{1}$, \\ Karka Srinivas Reddy², Avvari Sanjeeva Kumar ${ }^{3}$ \\ ${ }^{1}$ Department of Pharmacognosy, Netaji Institute of Pharmaceutical Sciences, Toopranpet, Nalgonda. Andhra Pradesh, India \\ 2Department of Pharmacognosy, Vaagdevi College of Pharmacy, Ramnagar, Hanamkonda, Andhra Pradesh, India \\ ${ }^{3}$ Division of Pharmacognosy, Raghavendra Institute of Pharmaceutical Education and Research, Krishnam Reddy Palli cross, \\ Chiyyedu, Anantapur-515721, Andhra Pradesh, India
}

\begin{abstract}
Present study deals with the pharmacological evaluation of anti diabetic activity in Corallocarpus epigaeus rhizomes. The selected plant was collected, shade dried and made into powder which was extracted by maceration method using ethanol as solvent. The extract thus obtained was subjected to standard battery of phytochemical screening. Anti diabetic activity was evaluated at two dose level in both normoglycaemic and hyperglycemic rats. From these results it can be understood that plant extract showing its pharmacological action on diabetes between the time intervals of 1-2 hr after its administration. This is exactly what the action that is being observed from the standard Glibenclamide group which also shown its action at its 1-2 hr of administration to the animals. Here the statistically significant action of the higher dose of plant extract can be compared with that of the standard Glibenclamide group. From these results it can be understood that the plant extract is capable of inhibiting the elevation of blood glucose level to the extent of the action that has been shown by the standard Glibenclamide group. Particularly at the time interval of 2-4 hr both the Glibenclamide and plant extract at its high dose group that is $400 \mathrm{mg} / \mathrm{kg}$ has been significantly inhibited the elevation of the blood glucose levels in the animals.
\end{abstract}

Key Words: Corallocarpus epigaeus, herbal medicine, ethanolic extract, phyto constitutes, acute toxicity, haemoglucostrips, flavoniods.

\section{INTRODUCTION}

Herbal medicine is the oldest form of medicine in India and China. However, now it is the most widely used system of medicine in the entire world today. Herbal medicines have several advantages if they are well researched. If we pool the knowledge from diverse traditions, we have a cure for just above every illness known to the man. More over many drugs are been discovered from the plants which are used in treating dreadful diseases like cancer and diabetes. (Nisha et al., 2010) Hence in order to quench the thirst for a new drug for an ailment from herbal origin the plant 'Corallocarpus epigaeus' has been chosen.

Corallocarpus epigaeus Rottl.ex.wild (Cucurbitaceae) is a prostrate or climbing monoecious plant found in

\footnotetext{
*Corresponding Author:

Kattamanchi Gnananath, Assistant Professor

Department of Pharmacognosy

Netaji Institute of Pharmaceutical Sciences

Toopranpet, Nalgonda. Andhra Pradesh, India

E-mail:k.gnananath@gmail.com

Contact No.: +919948700602
}

tropical countries like India, Ceylon, Deccan and South Maratha. The plant is indigenously known as Murdonda, Nagadonda in Telugu, and Akasgaddah in Hindi (Kirthikar et al., 1996). The plant is reported to contain a sesquiterpene, lactone-corallocarpenoyl ester and an aliphatic $\mathrm{C}_{32}$ keto diol (Kirthikar et al., 1996). The roots and rhizomes are having many traditional claims especially in syphilitic cases, old venereal complaints, and chronic dysentery (Nadkarni et al., 1982). It is also an effective remedy for diabetes (Chetty et al., 2004), herpes, and Anthelmintic (Ali et al., 1996), rheumatism and snake bite (Chopra et al., 1956). Decoction of powder root has given benefit in cases of chronic mucous enteritis (Ali et al., 1996). Even though the plant has good therapeutic use and traditional claims for diabetes, till now no scientific study was available on the anti diabetic activity of Corallocarpus epigaeus. Hence, the present study deals with the Anti diabetes evaluation in the rhizomes of Corallocarpus epigaeus. 


\section{MATERIALS AND METHODS}

\section{Collection of plant material}

Corallocarpus epigaeus rhizomes were collected during the months of March and April, 2012 from Athmakur [Mandal], Nalgonda, Telangana region, Andhra Pradesh, India. The collected plant material were identified and authenticated by Ms. Sitha Devi, Department of Botany, New Era Junior College, Hyderabad, AP, India. The voucher specimen (KG/COG/2012/01) was deposited in the Department of Pharmacognosy, Netaji institute of pharmaceutical science, Toopranpet, Nalgonda, Andhra Pradesh, India for future reference.

\section{Extraction of plant material}

The collected plant material was thoroughly checked for foreign matter, earthy matter and washed twice with water. Then they were dried well in shade and coarsely powdered using electronic pulverizer. The coarsely powdered plant material was subjected to maceration with ethanol as solvent for $72 \mathrm{hr}$. After 72 hours, the contents were filtered carefully and the extract obtained was concentrated under vacuum and stored in desiccators till its further use. The extract was designated as EECE (Prashanth et al., 2011; Ncubi et al., 2008).

\section{Phytochemical screening}

The ethanolic extract of Corallocarpus epigaeus was subjected to various qualitative chemical tests for the identification of phyto constituents present in them (Vinod et al., 2004; Khandelwal et al., 2003).

\section{Experimental animals}

Adult Wistar rats (150-200g) and Swiss albino mice (for toxicity studies) of either sex were used in the studies. The animals were kept in standard polypropylene cages at room temperature of $30 \pm 2^{\circ} \mathrm{C}$ and $60-65 \%$ relative humidity. All the experimental procedures were approved by Institutional animal ethical committee (IAEC) of Vaagdevi College of Pharmacy, Hanamkonda, Andhra Pradesh, India vide approval No. 1047/AC/09/CPCSEA.

\section{Acute toxicity studies}

Swiss albino mice of either sex (20-25 g weight) were used for acute oral toxicity study. The study was carried out as per the guidelines set by OECD 423 . Animals were divided into three groups, three animals each. Group I received normal saline which serves as control and as there were no acute toxicity studies was performed earlier for this plant, a dose of $300 \mathrm{mg} / \mathrm{kg}$ and $2000 \mathrm{mg} / \mathrm{kg}$ was given orally to group II and III. Animals were observed for the 14 days period for any toxicity and gross behavioral changes (OECD guidelines 1996).

\section{Evaluation of antidiabetic activity}

The anti diabetic screening of the ethanolic extract of Corallocarpus epigaeus was studied on both alloxan induced diabetic rats and normoglycaemic rats.

\section{Using hyperglycaemic rats}

The acclimatized animals were kept fasting for 24 hours and injected intra peritoneally a dose of 120 $\mathrm{mg} / \mathrm{kg}$ of alloxan monohydrate in normal saline. After one hour, the animals were provided feed ad libitum. The blood glucose level was checked before alloxanisation and $24 \mathrm{~h}$ after alloxanisation by withdrawing blood from the tip of the tail of each rat under mild ether anaesthesia. The blood glucose level was measured with haemoglucostrips supplied by M/s Pulsatum Health Care Pvt. Ltd., Bangalore, India with the help of a Pulsatum ${ }^{\circledR}$ blood glucose monitor. Animals were considered diabetic when the blood glucose level was raised beyond $200 \mathrm{mg} / 100 \mathrm{ml}$ of blood. This condition was observed at the end of $48 \mathrm{~h}$ after alloxanisation. The animals were segregated into four groups of six rats in each. Group-I served as control and received vehicle $(2 \mathrm{ml} / \mathrm{kg})$ through oral route. Group-II received Glibenclamide $(2.5 \mathrm{mg} / \mathrm{kg})$. Group-III and IV received the EECE at doses of 200 and $400 \mathrm{mg} / \mathrm{kg}$ in a similar manner. Blood samples were collected from each rat by cutting the tip. Blood glucose level was estimated at $0 \mathrm{~h}, 1 \mathrm{~h}, 2 \mathrm{~h}, 4 \mathrm{~h}$ and 8 $\mathrm{h}$ respectively (Srinivas et al., 2011).

\section{Using normoglycaemic rats}

The animals were fasted for 18 hours, but were allowed free access to water before and throughout the duration of experiment. At the end of the fasting period, taken as zero time $(0 \mathrm{~h})$, blood was withdrawn from the tip of the tail of each rat and the blood glucose was estimated as above. The normal rats were then divided into four groups of six animals each. Group-I served as control and received vehicle $(2 \mathrm{ml} / \mathrm{kg})$ through oral route. Group-II received Glibenclamide $(2.5 \mathrm{mg} / \mathrm{kg})$. Group-III and IV received EECE at doses of 200 and $400 \mathrm{mg} / \mathrm{kg}$ in a similar manner. Blood glucose levels were monitored after 1, 2, 4 and $8 \mathrm{~h}$ of administration of single dose of test samples (Srinivas et al., 2011). 


\section{Statistical analysis}

The Mean \pm S.E.M. Significance of differences between control and treated groups was determined using Student's $t$-test and the level of significance was set accordingly.

\section{RESULTS AND DISCUSSION}

\section{Extraction}

The \% yield of the ethanolic extract of Corallocarpus epigaeus rhizomes was found to be $3.56 \% \mathrm{w} / \mathrm{w}$.

\section{Preliminary phytochemical screening}

The preliminary phytochemical screening revealed the presence of phenolic compounds, Flavonoids, tri terpinoids and phytosterols. The results were shown in table 1.

\section{Acute toxicity studies}

The animals were then observed continuously for first four hours for any behavioral changes and for mortality if any at the end of 14 day. No mortality was observed in the animals tested up to 2000 $\mathrm{mg} / \mathrm{kg}$ test doses. Hence, EECE at a dose of 200 and $400 \mathrm{mg} / \mathrm{kg}$ were selected for the present study.

\section{Antidiabetic activity}

The purpose of choosing alloxan monohydrate as the diabetes-inducing agent was that it is known to produce diabetes mellitus irreversibly with a single dose administration by selective necrotic action on the beta cells of pancreas leading to insulin deficiency. Insulin deficiency leads to various metabolic aberrations in animals viz., increased blood glucose level, decreased protein content, increased levels of cholesterol and triglyceride. It is well known that the level of glycemic control is the major determinant of serum level of triglyceride. Several investigators demonstrated that near normalization of the blood glucose level resulted in significant reductions in levels of plasma cholesterol, and triglyceride level.

In alloxan induced model, the control group animals shown blood glucose levels as 232.06, 235.86, 248.48, 265.52 and $289.41 \mathrm{mg} / \mathrm{dL}$ at time intervals of $0,1,2,4$ and 8 hour, respectively whereas the EECE has been shown the blood glucose levels of 237.01, 210.1, $175.09,168.82 \& 150.8 \mathrm{mg} / \mathrm{dL}$ at time intervals of 0,1 , 2,4 \& 8 hour, respectively at lower dose $(200 \mathrm{mg} / \mathrm{kg})$
Table 1: Preliminary phytochemical screening of EECE.

\begin{tabular}{ccc}
\hline $\begin{array}{r}\text { Sl. } \\
\text { No. }\end{array}$ & Phytoconstituents & Result \\
\hline 1 & Alkaloids & - \\
2 & Carbohydrates & - \\
3 & Glycosides & - \\
4 & Saponins, proteins \& Amino acids & - \\
5 & Phenolic compounds & + \\
6 & Tannins & - \\
7 & Gums and mucillages & - \\
8 & Flavonoids & + \\
9 & Fixed oils\& fats & - \\
10 & Volatile oils & - \\
11 & Tri terpenoids & + \\
12 & Phytosterols & - \\
\hline
\end{tabular}

and 257.8, 243.65, 185.8, 129.8 and $104.1 \mathrm{mg} / \mathrm{dL}$ at time intervals of $0,1,2,4$ and 8 hour, respectively at its higher dose group $(400 \mathrm{mg} / \mathrm{kg})$. From this results it can be understood that EECE showing its pharmacological action on diabetes between the time interval of $1-2 \mathrm{hr}$ after its administration. This is exactly what the action that is being observed from the standard Glibenclamide group which also shown its action at its $1-2 \mathrm{hr}$ of administration to the animals. Here the statistically significant action of the higher dose of EECE can be compared with that of the standard Glibenclamide group (Table 2).

In normal model, the control group animals shown blood glucose levels as 92.6, 95.1, 96.27, 97 and 98.34 $\mathrm{mg} / \mathrm{dL}$ at time intervals of $0,1,2,4$ and 8 hour, respectively where as the EECE has been shown the blood glucose levels of 92.14, 90.1, 89.14, 83.64 and $79.9 \mathrm{mg} / \mathrm{dL}$ at time intervals of $0,1,2,4$ and 8 hour, respectively at lower dose that is $200 \mathrm{mg} / \mathrm{kg}$ and $88.1,85.18,80.66,71.8$ and $63.8 \mathrm{mg} / \mathrm{dL}$ at time intervals of $0,1,2,4$ and 8 hour, respectively at its higher dose group that is $400 \mathrm{mg} / \mathrm{kg}$. From these results it can be understood that the plant extract is capable of inhibiting the elevation of blood glucose level to the extent of the action that has been shown by the standard Glibenclamide group. Particularly at the time interval of $2-4 \mathrm{hr}$ both the Glibenclamide and EEC at its high dose group that is $400 \mathrm{mg} / \mathrm{kg}$ has been significantly inhibited the elevation of the blood glucose levels in the animals. Here the statistically significant action of the higher dose of EECE can be compared with that of the standard Glibenclamide group (Table 3). 
Table 2: Effect of Corallocarpus epigaeus on the blood glucose concentration in alloxan induced hyperglycaemic rats.

\begin{tabular}{|c|c|c|c|c|c|c|}
\hline \multirow{2}{*}{ Group } & \multirow{2}{*}{ Treatment } & \multicolumn{5}{|c|}{ Blood glucose conc. (mg/dl.) } \\
\hline & & Oh & 1h & $2 \mathrm{~h}$ & $4 \mathrm{~h}$ & $8 \mathrm{~h}$ \\
\hline I & $0.5 \% \mathrm{w} / \mathrm{v}$ Sodium CMC $(2 \mathrm{ml} / \mathrm{kg})$ & $232.06 \pm 10.1$ & $235.86 \pm 12.4$ & $248.48 \pm 11.87$ & $265.52 \pm 12.46$ & $289.41 \pm 8.96$ \\
\hline II & Glibenclamide $(2.5 \mathrm{mg} / \mathrm{kg})$ & $280.6 \pm 22.4$ & $190.16 \pm 16.8^{*}$ & $125.6 \pm 8.84^{* *}$ & $91.67 \pm 4.84^{* *}$ & $86.1 \pm 3.2^{* *}$ \\
\hline III & EECE $(200 \mathrm{mg} / \mathrm{kg})$ & $237.01 \pm 10.1$ & $210.10 \pm 14.6$ & $175.09 \pm 14.2^{*}$ & $168.82 \pm 16.4^{*}$ & $150.8 \pm 10.6^{* *}$ \\
\hline IV & EECE $(400 \mathrm{mg} / \mathrm{kg})$ & $257.8 \pm 10.66$ & $243.65 \pm 14.64$ & $185.8 \pm 16.18^{*}$ & $129.8 \pm 12.4^{* *}$ & $104.1 \pm 9.2^{* *}$ \\
\hline
\end{tabular}

Results expressed as Mean \pm S.E.M from six observations. ${ }^{*} \mathrm{P}<0.01$; ${ }^{* *} \mathrm{P}<0.001$

Table 3: Effect of Corallocarpus epigaeus on the blood glucose concentration in normoglycaemic rats.

\begin{tabular}{|c|c|c|c|c|c|c|}
\hline \multirow{2}{*}{ Group } & \multirow{2}{*}{ Treatment } & \multicolumn{5}{|c|}{ Blood glucose conc. (mg/dl.) } \\
\hline & & Oh & 1h & $2 \mathrm{~h}$ & $4 h$ & $8 \mathrm{~h}$ \\
\hline $\mathrm{I}$ & $0.5 \% \mathrm{w} / \mathrm{v}$ Sodium CMC (Vehicle) & $92.16 \pm 4.6$ & $95.1 \pm 3.17$ & $96.27 \pm 4.62$ & $97 \pm 5.02$ & $98.34 \pm 3.21$ \\
\hline II & Glibenclamide $(2.5 \mathrm{mg} / \mathrm{kg})$ & $98.32 \pm 3.1$ & $90.66 \pm 4.72^{*}$ & $83.23 \pm 5.2^{* *}$ & $70.6 \pm 2.1^{* *}$ & $62.1 \pm 5.8^{* *}$ \\
\hline III & EECE $(200 \mathrm{mg} / \mathrm{kg})$ & $92.14 \pm 3.2$ & $90.1 \pm 4.17$ & $89.14 \pm 4.74$ & $83.64 \pm 4.9^{*}$ & $79.9 \pm 5.1 * *$ \\
\hline IV & EECE $(400 \mathrm{mg} / \mathrm{kg})$ & $88.1 \pm 3.1$ & $85.18 \pm 6.33$ & $80.66 \pm 2.3^{*}$ & $71.8 \pm 2.6^{* *}$ & $63.8 \pm 3.17^{* *}$ \\
\hline
\end{tabular}

Results expressed as Mean \pm S.E.M from six observations. ${ }^{*} \mathrm{P}<0.01 ;{ }^{* *} \mathrm{P}<0.001$

\section{CONCLUSION}

From the above study, it can be concluded that the ethanolic extract of Corallocarpus epigaeus rhizomes possesses the antidiabetic action which is comparable with that of the standard Glibenclamide drug employed. This work supports the traditional claim of the rhizomes for their use in diabetes.

\section{ACKNOWLEDGEMENT}

The authors express their thanks to Ms. Sitha Devi, New Era Junior College, Hyderabad, AP, India for authentication of plant material and express their great gratitude to the management, principal and faculty of Pharmacognosy from both Netaji Institute of Pharmaceutical Sciences, Toopranpet, Nalgonda, Andhra Pradesh, India and Vaagdevi College of Pharmacy, Ramnagar, Hanamkonda, Andhra Pradesh, India for providing necessary facilities for conducting this work.

\section{REFERENCES}

Ali, M., Gupta, J. (1996). Chemical Constituents of Corallocarpus epigaeus rhizomes. Journal of Medicinal and Aromatic plant sciences, Volume 18, issue 4, pages 791-794.

Chetty, K. M., Shivaji, K., Tulasi K. R. (2004). Flowering plants of Chittoor district Andhra Pradesh, India (2 ${ }^{\text {nd }}$ ed., pp 138). Tirupathi: Student offset printers.

Chopra, R.N., Nayar, S.C., Chopra, I.C. (1956). Glossary of Indian Medicinal Plants (1 ${ }^{\text {st }}$ ed., pp 980). New Delhi: Council of scientific and industrial research.

Khandelwal KR, Practical Pharmacognosy, $10^{\text {th }}$ edition, Nirali prakashan, Pune, 2003:38-161.
Kirtikar, K.R. \& Basu, B.D. (1996). Indian Medicinal Plants (2nd ed., Volume II, pp 1664). Allahabad (India): Lalit Mohan Basu.

Nadkarni, K.M. (1982). The Indian Materia Medica (1 ${ }^{\text {st }}$ ed., Volume I, pp 377). Bombay: Popular Prakashan.

Ncube, N.S., Afolayan, A.J., Okoh, A.I. (2008). Assessment techniques of antimicrobial properties of natural compounds of plant origin: current methods and future trends. African Journal of Biotechnology, Volume 7, Issue 12, pages 1797-1806

Nisha, C.S., Balaji, J., Venkatramanan, S., Madhumathi, K.L. (2010). Pharmacognostical and preliminary phytochemical screening of the root and rhizome of Corallocarpus epigaeus International Journal of Pharmaceutical Biomedical Research, Volume1, Issue 1, pages 24-27.

Nisha, S.C., Balaji, J.S. Venkatramanan, K, Madhumathi L. (2010). Pharmacognostical and preliminary phytochemical screening of the root and rhizome of Corallocarpus epigaeusInt J Pharm Biomed Res, Volume1, Issue 1, pages 24-27.

Organization for Economic Cooperation and Development. OECD guidelines for testing of chemicals. Guideline 423, acute oral toxicity - acute toxic class method. Adopted March 22, 1996.

Prashant, T., Bimlesh, K., Mandeep, K., Gurpreet, K., Harleen, K. (2011). Phytochemical screening and Extraction- A Review. Internationale Pharmaceutica Sciencia, Volume 1, Issue 1, pages 98-106.

Srinivas, R.K., Sanjeeva, K.A., Ganapaty, S. (2011). Evaluation of Hypoglycemic and Wound healing activities of Lantana wightiana Wall. Ex Gamble leaves. International Research Journal of Pharmacy, Volume 2, Issue 12, Pages 264-266.

Srinivas, R.K., Sanjeeva, K.A., Ganapaty, S. (2011). Pharmacological screening of Scoparia dulcis roots for hypoglycaemic activity. International Journal of Pharmacy and Pharmaceutical sciences, Volume 4, Issue 3, pages 367-369.

Vinod Rangari D, Pharmacognosy and Phytochemistry, $1^{\text {st }}$ edition, Career publications, Nashik, 2004:129-50. 